\title{
TUTORIA ATIVA: A MEDIAÇÃO COMO FATOR DE ENGAJAMENTO DO ALUNO EAD DA UNOPAR
}

\author{
LONDRINA/PR MAIO/2018
}

\author{
Adriano Rosa Alves - UNOPAR - adriano.alves@kroton.com.br \\ Thiago Nunes Bazoli - UNOPAR - thiago.bazoli@kroton.com.br \\ Lissandro de Sousa Falkowiski - UNOPAR - lissandro.falkowiski@kroton.com.br \\ Fernando Ciriaco - UNOPAR - fernandod@kroton.com.br \\ Karen Hiramatsu Manganotti - UNOPAR - karen.manganotti@kroton.com.br \\ Renata Karoline Fernandes - UNOPAR - renata.karoline@kroton.com.br
}

Tipo: Relato de Experiência Inovadora (EI)

Categoria: Métodos e Tecnologias

Setor Educacional: EDUCAÇÃO SUPERIOR

\begin{abstract}
RESUMO
A mediação na educação a distância tem como um dos principais objetivos a orientação acadêmica, o auxílio pedagógico e a inferência a respeito da aprendizagem dos alunos. Para isso o tutor a distância deve possuir, além de suas competências e habilidades, ferramentas que possam auxiliar o desenvolvimento de suas atividades. Pensando na importância que a mediação tem para a formação dos alunos que optam pela modalidade de Educação a Distância, a Universidade Pitágoras Unopar UNOPAR desenvolveu um projeto piloto chamado Tutoria Ativa. Este projeto estimula uma atuação proativa do tutor junto aos alunos, servindo-se de uma régua de comunicação constituída por meio de um cronograma semestral. O presente relato aborda a experimentação deste projeto piloto aos alunos dos cursos Superior de Tecnologia em Marketing e Licenciatura em Artes Visuais no segundo semestre de 2016, observando resultados obtidos na pesquisa de satisfação aplicada aos alunos matriculados nestes dois cursos. Para esse trabalho foi utilizada a metodologia de estudo de caso, pesquisa exploratória e descritiva com abordagem qualitativa, e fontes de dados primários e secundários. Para realizar a análise dos dados foram relatados modelos de mensagens enviadas aos alunos, bem como, o resultado da pesquisa de satisfação quanto a atuação mediadora dos tutores.
\end{abstract}

Palavras-chave: Educação a Distância, Tutoria Ativa, Mediação, Engajamento. 


\section{Introdução}

Pensar em novos modelos para a educação a distância implica em refletir a respeito dos papéis dos principais sujeitos do processo de aprender e ensinar. Quando analisamos as metodologias aplicadas e às ferramentas disponíveis, para essa modalidade de ensino e, atuação dos atores envolvidos no processo de ensino e aprendizagem, devemos refletir que não basta somente oportunizarmos excelentes ferramentas virtuais e plataformas de aprendizagem, pois, segundo Chules e Rabelo (2015), não basta somente termos plataformas que auxiliem os alunos de forma eficiente, mas também, às Instituições de Ensino devem dispor de professores e tutores que apresentem um perfil que permita mediação plena, estando aptos a planejarem e desenvolverem situações e vivências que possibilitem aos alunos desenvolverem suas capacidades por meio dos estudos.

O saber e os caminhos construtivos do conhecimento, podem ser trilhados a partir dos conhecimentos empíricos que os discentes já possuem, assim como, o conteúdo que o professor disponibiliza em suas aulas, materiais e atividades. Porém, cabe ressaltar que, para que o propósito da mediação seja alcançado, necessita-se do tutor a distância. É possível recorrer aos estudos de Moran (2015, p. 28), em que o autor afirma que "a aprendizagem se constrói em um processo equilibrado entre a elaboração coletiva - por meio de múltiplas formas de colaboração em diversos grupos - e a personalizada - em que cada um percorre roteiros diferenciadores". Cabe então aos tutores a distância criarem um processo de mediação em que o aluno possa ser assistido de forma construtiva, possa compreender os conteúdos e gerar os resultados esperados.

Sendo assim, o presente artigo contempla a verificação do projeto piloto "Tutoria Ativa", aplicado no segundo semestre de 2016 na Universidade Pitágoras Unopar - UNOPAR, na modalidade de Educação a Distância, relatando a aplicação da régua de comunicação proativa com os alunos matriculados nos cursos de CST em Marketing e Licenciatura em Artes Visuais e os resultados obtidos através de uma pesquisa de satisfação aplicado aos alunos envolvidos neste projeto.

\section{Objetivos}

O presente artigo tem como objetivo apresentar, por meio do projeto tutoria ativa aplicado na UNOPAR na modalidade EaD, a importância da mediação como um mecanismo de engajamento, e forma de contribuir para a formação do estudante.

\section{Referencial Teórico}

O ensino a distância vem conquistando cada vez mais espaços no meio acadêmico. Esta modalidade é adotada pelos estudantes que necessitam de uma maior flexibilidade 
quanto ao tempo para realizar seus estudos e estudos. Em nosso país, a ampla extensão territorial tem sido um motivador para a expansão desta modalidade. No Brasil, o conceito de ensino a distância foi definido pela Presidência da República por meio do Decreto 5.622, de 19 de dezembro de 2005 (BRASIL, 2005). Afirma Moore e Kearsley (2013, p. 8) que "a tecnologia continua a avançar em velocidade vertiginosa, levando à transformação do pensamento sobre como aprendemos e forçando a revisão do pensamento sobre como ensinamos". Estas transformações nas formas de ensinar, especialmente pela modalidade de Educação a Distância - EaD, contribuiu para a formação de grupos que debatem constantemente sobre este assunto: os favoráveis, os quais apoiam e realizam pesquisas sobre este modelo e, aqueles que são contrários a esta metodologia de ensino.

A respeito do processo de mediação, cabe destacar que para sua eficiência, o tutor que o realiza deve compreender a estrutura do conteúdo das disciplinas, tendo formação teórica sobre o contexto, este necessita entender a estrutura do assunto que está sendo ministrado pelos professores durante as teleaulas. Sua formação teórica sobre o contexto pedagógico-didático deverá ser sempre atualizada com uma formação prática para maior interação com seus alunos no Ambiente Virtual de Aprendizagem - AVA. (MACHADO; MACHADO. 2004). Pensando nesta capacitação e melhoria nos processos de mediação com os alunos matriculados na modalidade de ensino a distância, a UNOPAR desenvolveu e implementou um projeto piloto no segundo semestre de 2016, a Tutoria Ativa. Esta surgiu para aprimorar as atividades de mediação pedagógica dos tutores a distância, revisitando rotinas, atribuições, sistema e ambiente virtual, criando espaço virtual de acompanhamento tutorial, estabelecendo indicadores para a gestão e controle do processo, imprimindo maior qualidade de ensino (FALKOWISKI, 2018).

A implantação da tutoria ativa e da régua de comunicação foi para contribuir com a melhoria na qualidade do ensino gerando uma maior efetividade do acompanhamento por parte dos tutores com vossos respectivos alunos, sendo assim, os benefícios esperados após a implementação desta metodologia foram: melhoria na qualidade do ensino, maior efetividade no acompanhamento tutorial, maior interação entre o tutor e o aluno, contribuição para a redução do índice de evasão e, maior assistência aos alunos. Logo, a tutoria ativa surge para aumentar a interação entre alunos e tutores, bem como, a difundir uma comunicação proativa, incentivando o aluno a desenvolver todas as suas atividades e estar participando e utilizando todas as ferramentas que a IES disponibiliza para que ele possa ter uma maior aderência aos assuntos ministrados e abordados nas temáticas das aulas.

O tutor não ensina no sentido convencional da palavra, como também não dá aulas, 
nem produz materiais, ele atua como um mediador em todos os processos do ensino (CABANAS; VILARINHO. 2007). A proatividade do tutor a distância é fundamental na construção de suas ações, proporcionando ao aluno as orientações necessárias para realização de seus estudos e também cumprimento de suas atividades, proporcionando ao mesmo o aprendizado necessário referente a cada disciplina e conteúdo (ALVES, 2017).

Logo, para que ocorra esta proatividade do tutor a distância, é fundamental o conhecimento do cronograma de atividades de cada semestre que ele assiste. Considera-se cronograma de atividades o documento oficial da instituição em que constam todas as datas dos fatos geradores, para a elaboração das regras para estas e outras atividades. É de responsabilidade do tutor a distância a elaboração do calendário de atividades, mensagens referentes ao semestre letivo em que atua. De posse do Cronograma de atividades disponível no AVA e das orientações sobre as regras e fatores geradores, o tutor a distância tem todas as condições necessárias para elaboração e cumprimento do Calendário de Atividades (FALKOWISKI, 2018). Os fatos geradores para que ocorra uma mediação e comunicação intensiva entre os tutores a distância e os alunos são: as webaulas, as teleaulas, as provas presenciais e a produção textual interdisciplinar.

Podemos observar então que, diante das necessidades e possíveis dificuldades que os alunos possam encontrar durante sua permanência na IES, a tutoria ativa, por meio dos fatos geradores apontados, elaborou uma régua de comunicação para antecipar qualquer questionamento que viesse a surgir por parte dos alunos quanto ao como, quando e onde fazer uma atividade ou, para antecipar uma informação referente aos conteúdos didáticos, acesso à materiais, entre outros. Esta régua de comunicação estabelecida diante do cronograma de atividades que é disponibilizada para alunos, assistentes, tutores e professores, irá produzir estímulos para que os alunos possam efetivamente participar das aulas e obtenham um melhor desempenho no desenvolvimento de suas atividades (FALKOWISKI, 2018).

\section{Procedimentos Metodológicos}

A construção do presente artigo baseou-se na dissertação $O$ trabalho do tutor frente a um novo modelo de tutoria (2018), em uma pesquisa de satisfação aplicada aos alunos dos cursos de CST em Marketing e Licenciatura em Artes Visuais, bem como, no arcabouço teórico dos autores que discutem a EaD e qual o papel do tutor no processo de ensino e aprendizagem do discente quanto às mediações realizadas e, os documentos disponibilizados pela Universidade Pitágoras Unopar - UNOPAR localizada na cidade de Londrina/PR. 
Desta forma, seguimos um percurso metodológico que envolveu uma pesquisa bibliográfica em livros, artigos e dissertações que discorriam sobre a temática pesquisada. A pesquisa fora do tipo exploratória para o levantamento do referencial teórico e descritiva para o registro e análise dos dados apurados, pois, de acordo com Kotler e Keller (2006), a pesquisa exploratória tem como principal característica a informalidade, flexibilidade e criatividade, procurando obter um primeiro contato com a situação a ser pesquisada. O artigo também abarcou uma pesquisa descritiva, pois, observou, registrou e analisou dados obtidos através de um instrumento aplicado pela IES. Segundo Marconi e Lakatos (1991), a pesquisa de caráter descritiva busca descrever um fenômeno através de seu estudo, sendo, portanto, flexível a toda e qualquer variação no tempo e no espaço.

Sobre a abordagem da pesquisa, de acordo com os estudos de Cruz (2009) e Fregoneze et al. (2014), optou-se pela pesquisa qualitativa, pois, há uma análise do tema proposto de forma mais livre, ao se trabalhar com descrições, comparações, interpretações e atribuição de significados, sendo possível investigar valores, crenças, hábitos, atitudes e opiniões dos participantes pesquisados. Segundo os estudos de Martins e Theóphilo (2007, p. 135), as pesquisas qualitativas "pedem descrições, compreensões e análises de informações, fatos, ocorrências que naturalmente não são expressas por números". Assim, observou-se a necessidade de realizar-se um diálogo entre o meio social e seus participantes, analisando os efeitos que a aplicação da régua de comunicação pode gerar aos discentes que participaram da pesquisa. Trata-se também de uma pesquisa dedutiva. Bastos e Keller (2002, p. 84-85) destacam a dedução como um método onde você "descobre uma verdade a partir de outras verdades que já conhecemos".

Para ancorarmos a caracterização dos dados, recorreu-se à análise de conteúdo, conforme proposto por Bardin (2011). De forma sintetizada, de acordo com o pesquisador, "a análise de conteúdo pode ser uma análise dos 'significados' (exemplo: a análise temática), embora possa ser também uma análise dos 'significantes' (análise lexical, análise dos procedimentos)" (BARDIN, 2011, p. 41). Tais asseverações possibilitaram agrupar os argumentos dos participantes por traços de similaridade.

\section{Apresentação e discussão dos resultados}

A mediação entre os atores envolvidos no processo de ensino e aprendizagem, onde destaca-se o tutor a distância e aluno, é de suma importância para que o aluno possa ter um melhor aproveitamento de todas as ferramentas e aulas que são disponibilizadas, aumentando seus conhecimentos e, também, diminuindo o risco de evasões por falta de atendimento apropriado (ALVES, 2017). 
Nesta dinâmica da EaD, surge a importância do tutor a distância, que, de acordo com a pesquisa realizada por SILVEIRA (s/d), pode ser definido como: “(...) aquele que instiga a participação do aluno, evitando a desistência, o desencantamento pelo saber. Talvez, aquele que possibilita a construção coletiva (...)" (p. 2). Corrobora com esta consideração a pesquisa de Borges e Souza (2012), onde, os autores nos apresentam que a tutoria mediadora vem para atender as necessidades do aluno e indicar as oportunidades que o curso e as ferramentas disponíveis podem oferecer, atuando o tutor com comprometimento para que o aluno possa construir sua aprendizagem autônoma, através da interação virtual.

As orientações enviadas para os alunos compreendem os seguintes pontos: apresentação e boas-vindas aos alunos, avisos sobre os prazos das atividades, mediação junto ao fórum, orientações sobre o desenvolvimento de atividades, considerações sobre o cumprimento dos prazos, acesso aos materiais para estudo não somente para realização das provas, acompanhamento do aluno em suas possíveis dúvidas, envio de mensagens motivacionais, correção das atividades realizada pelos alunos (por meio de gabarito disponibilizado pelos professores), acompanhar os chats de aula, atividades e provas presenciais e, realizar uma interação geral sempre procurando despertar no aluno a participação maciça em todos os momentos que o curso proporciona. A seguir, apresentamos alguns modelos e mensagens que foram enviadas aos alunos através da régua de comunicação aplicada no projeto piloto:

\section{Figura 1: Boas-vindas - Tutoria ativa}

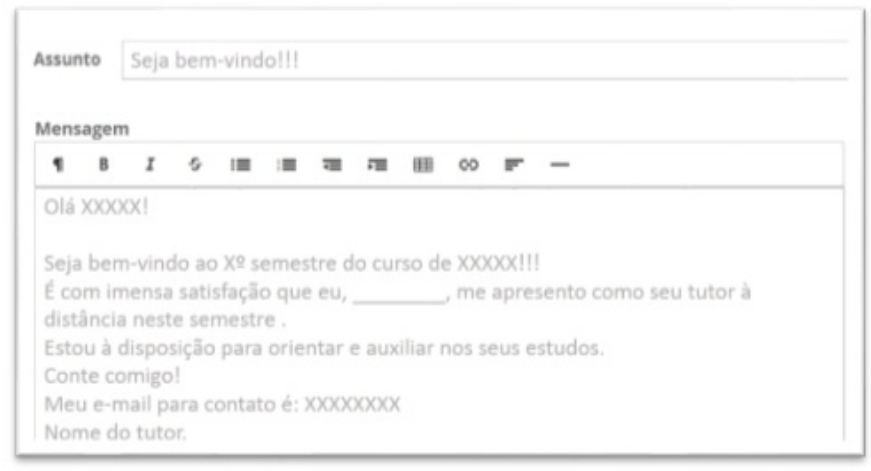

Fonte: dos autores (2018).

Figura 2: Avaliação Virtual - Tutoria ativa. 


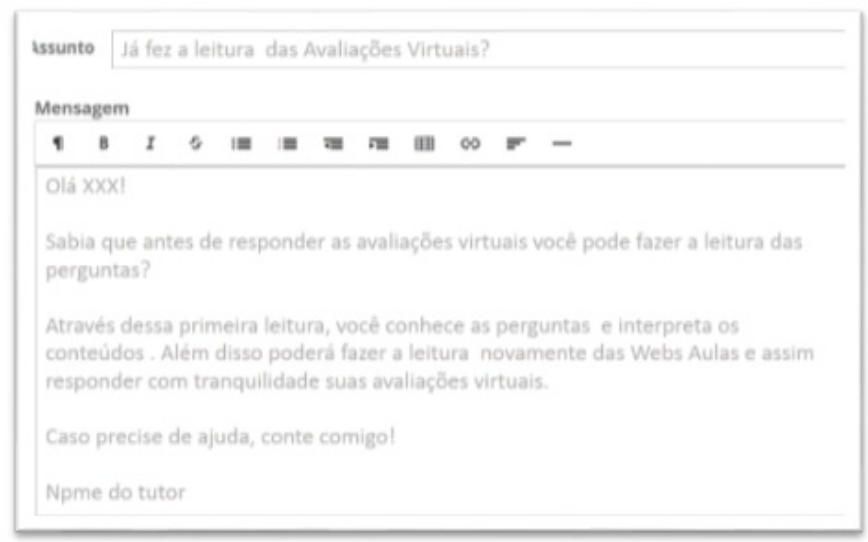

Fonte: dos autores (2018).

Os cursos contemplados no projeto piloto com a implantação da tutoria ativa e da utilização da régua de comunicação foram o CST em Marketing e a Licenciatura em Artes Visuais, totalizando dois mil e quatrocentos alunos (2.400). Destes, 22,9\%, ou seja, quinhentos e cinquenta (550) alunos, responderam uma pesquisa de satisfação pontuando de zero (0) a quatro (4) a mediação realizada pelos tutores a distância durante todas as atividades desenvolvidas no segundo semestre de 2016. Após a aplicação do questionário e a obtenção das informações, fora apurado a pontuação média para cada tópico conforme demonstrado a seguir:

Gráfico 1: Avaliação dos alunos quanto a Mediação dos Tutores.

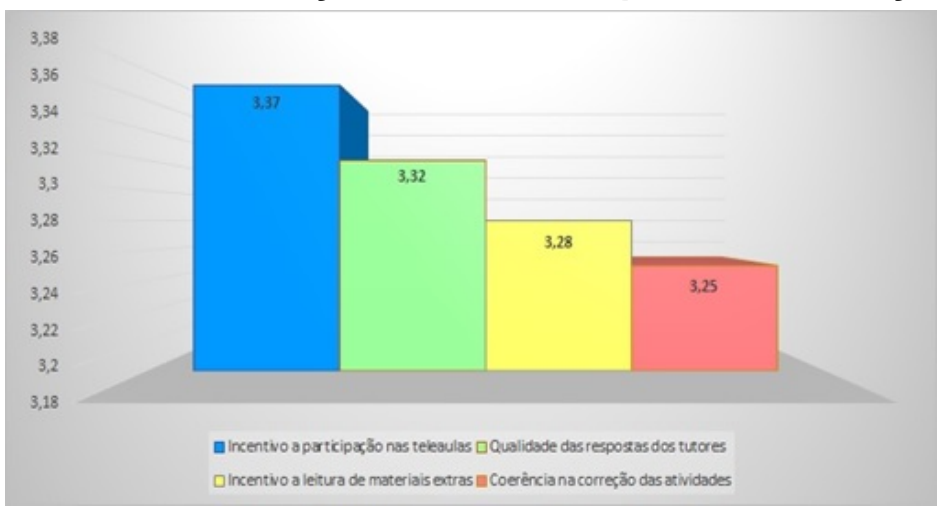

Fonte: Pesquisa de Satisfação da Universidade Norte do Paraná (2017).

Como pode ser observado, na atribuição das notas aplicadas pelos alunos aos seus respectivos tutores e as atividades desenvolvidas, principalmente com relação ao incentivo a participação nas teleaulas, o incentivo a leitura de materiais extras, a qualidade da resposta dos tutores e a coerência na correção das atividades, todas ficaram acima de 3 pontos, comprovando que a mediação proativa, por meio da tutoria 
ativa e seguindo uma régua de comunicação para aumentar o engajamento do aluno, obteve um resultado positivo. Outro dado importante oriundo da pesquisa de satisfação nos apresenta que $18 \%$ dos alunos tem a pessoa do tutor a distância como um ator indispensável no processo de ensino na modalidade $\mathrm{EaD}$ e $55 \%$ dos alunos tem o tutor a distância como uma figura importante. Tais resultados obtidos na pesquisa de satisfação aplicada aos alunos, bem como, o respaldo dos tutores a distância dos dois cursos que contemplaram este projeto piloto, comprovou a efetividade da utilização da régua de comunicação proativa, motivando e auxiliando a um engajamento maior do aluno durante sua permanência na IES. De acordo com a pesquisa de Silva, Andrade e Silva (2011), o papel do tutor tem grande importância para a construção do conhecimento e o desenvolvimento pessoal e profissional. Logo, sua mediação precisa ser um diferencial para o aluno EaD.

\section{Considerações finais}

Após a análise dos resultados obtidos na pesquisa de satisfação aplicada aos alunos, bem como, o relato dos tutores a distância, pertencentes aos cursos CST em Marketing e Licenciatura em Artes visuais, consideramos que os objetivos esperados foram alcançados, pois, a mediação tornou-se proativa, onde, os tutores, com a utilização da régua de comunicação, mantiveram um maior contato com seus alunos, gerando a possibilidade de um maior engajamento do aluno em todas as atividades propostas.

A experiência obtida no projeto piloto da UNOPAR, foi considerada uma prática de sucesso do ponto de vista estratégico e operacional para a IES e refletiu positivamente na percepção de qualidade do aluno que participou deste novo modelo de mediação. Os tutores a distância durante a realização das reuniões acadêmicas, apontaram vários feedbacks onde os alunos relataram o seu contentamento com a proatividade dos tutores, bem como, o quanto os estímulos enviados foram favoráveis para o desenvolvimento das atividades e dos estudos.

Diante dos resultados positivos e das experiências vivenciadas, o projeto foi ampliado em 2017 para os demais cursos da UNOPAR EaD e, com capacitações e treinamentos realizados com os tutores a distância, bem como, melhorias consideráveis nas ferramentas de comunicação e interação, a qualidade da mediação para os alunos demonstrou crescimento vertiginoso, resultados estes que podem ser comprovados pela pesquisa de avaliação da instituição que fora disponibilizada para todos os alunos da IES em seu AVA, o Programa AVALIAR de 2017, material de insumo da CPA da IES.

Como proposição de estudos futuros para complementação do assunto propomos que seja aprofundado os efeitos que a Tutoria Ativa poderá proporcionar aos alunos 
formandos, observando todo o seu caminhar acadêmico, suas experiências enquanto aluno e o quanto a mediação o auxiliou para sua formação superior.

\section{Referências}

ALVES, Adriano Rosa. Novas tecnologias da informação e comunicação nos cursos do PRONATEC: estratégias metodológicas. 2017. Dissertação (Mestrado em Metodologias para o Ensino de Linguagens e suas Tecnologias) - Universidade Norte do Paraná Londrina, 2017. Disponível em:< https://s3.amazonaws.com/pgsskrotondissertacoes/646084b74f02020ce077d8616e5e850f.pdf>. Acesso em: 19 abr. 2018.

BARDIN, Laurence. Análise de conteúdo. São Paulo: Edições 70, 2011.

BASTOS, Cleverson Leite; KELLER, Vicente; MARTIM, Irineu; LENGRAND, Paul. Aprendendo a aprender: introdução à metodologia científica. 16. ed. Petrópolis: Vozes, 2002.

BRASIL. Decreto ํㅜ 5.622, de 19 de dezembro de 2005. Regulamento o art. 80 da Lei no 9.394, de 20 de dezembro de 1996, que estabelece as diretrizes e bases da educação nacional.

Disponível

em: http://portal.mec.gov.br/sesu/arquivos/pdf/portarias/dec5.622.pdf. Acesso em 05 abr. 2018.

BORGES, Fabiana Vigo A.; SOUZA, Eduardo Rodrigo de. Competências essenciais ao trabalho tutorial: estudo bibliográfico. 2012. Disponível em:< http://sistemas3.sead.ufscar.br/ojs/Trabalhos/178-957-2-ED.pdf>. Acesso em: 21 abr. 2018.

CABANAS, Maria Imaculada Chao; VILARINHO, Lúcia Regina Goulart. Educação a distância: tutor, professor ou tutor-professor? E-TIC: Universidade Estácio de Sá, 12 e 13 nov. 2007.2 Disponível em:< https://etic2008.files.wordpress.com/2008/11/unesamariainmaculada.pdf>. Acesso em: 20 abr. 2018.

CHULES, Magali Regina Kolakowski; RABELO, Antonio Pereira. Competências do tutor que contribuem ao bom desempenho do aluno na ead. Brasília, DF: 2015. Disponível em:<> Acesso em: 05 abr. 2018.

CRUZ, Vilma Aparecida Gimenes. Metodologia da pesquisa científica. São Paulo: Pearson Prentice Hall, 2009. 
FALKOWISKI, Lissandro de Sousa. O trabalho do tutor frente a um novo modelo de tutoria. 2018. 90 f. Dissertação (Mestrado em Metodologias para o Ensino de Linguagens e suas Tecnologias) - Universidade Norte do Paraná - UNOPAR, Londrina, 2018.

FREGONEZE, Gisleine Bartolomei et al. Metodologia científica. Londrina: Editora e Distribuidora Educacional S.A., 2014.

KOTLER, Philip; KELLER, Kevin Lane. Administração de marketing. Mônica Rosenberg, Brasil Ramos Fernandes, Cláudia Freire (Trad.). 12. ed. São Paulo: Pearson Prentice Hall, 2006.

MACHADO, Liliana Dias; MACHADO, Elian de Castro. O papel da tutoria em ambientes ead. $11^{\circ}$ Congresso Internacional de Educação a Distância: Abr./2004. Disponível em:< http://www.abed.org.br/congresso2004/por/pdf/022-TC-A2.pdf>. Acesso em: 20 abr. 2018.

MARTINS, Gilberto de Andrade; THEÓPHILO, Carlos Renato. Metodologia da investigação científica para ciências sociais aplicadas. São Paulo: Atlas, 2007.

MOORE; Michael G.; KEARSLEY, Greg. Educação a distância: sistemas de aprendizagem online. 3. ed. São Paulo: Cengage Learning, 2013.

MORAN, José Manuel. Educação híbrida: um conceito chave para a educação, hoje. In: BACICH, Lilian; TANZI NETO, Adolfo; TREVISANI, Fernando de Mello (Org.). Educação híbrida: personalização e tecnologia na educação. Porto Alegre: Penso, 2015, p. 23-39.

SILVA, Ari Gonçalves; ANDRADE, Luci Carlos; SILVA, Milene Bartolomei. Educação a distância: as novas tecnologias e o papel do tutor na perspectiva da construção do conhecimento.

Disponível

em:< http://www.abed.org.br/congresso2011/cd/46.pdf>. Acesso em: 19 abr. 2018.

SILVEIRA. Regina Lúcia Barros Leal da. A importância do tutor no processo de aprendizagem a distância. In: Revista Iberoamericana (ISSN: 1681-5653), s/d. Disponível em < https://rieoei.org/RIE/article/view/2815>. Acesso em: 18 abr. 2018. 